\title{
Infecção pelo HTLV-I/II no Estado da Bahia
}

\author{
HLTV-I/II infection in Bahia State, Brazil
}

\author{
Ana Pavlova C.R. Britto, Bernardo Galvão-Castro, Andrea Straatmann, \\ Sandro Santos-Torres e José Tavares-Neto
}

\begin{abstract}
Resumo A cidade do Salvador, capital do Estado da Bahia, apresenta a população com maior prevalência da infecção pelo HTLV-I no Brasil. Todavia, somente um estudo incluiu uma cidade do interior deste Estado, mesmo assim com número amostral pequeno. O objetivo foi o de avaliar a prevalência de anticorpos anti-HTLV-I/II na população de quatro cidades do interior do Estado da Bahia. As amostras de soro proveninentes de 1.539 indivíduos residentes em Catolândia, Ipupiara, Jacobina e Prado foram triadas através do ELISA, e a confirmação dos resultados nas amostras repetidamente positivas foi realizada através do "Western blot". Quarenta e sete (3,1\%) amostras foram positivas pelo ELISA, e 44 destas foram submetidas ao Western blot, com 5 resultados positivos (0,3\%), 8 (0,5\%) indeterminados (todos da cidade de Jacobina) e 31 negativos. A prevalência geral de anticorpos anti-HTLV-I, nas cidades estudadas, foi de 0,3\%. Esta prevalência variou de $0,0 \%$ (Prado) a $0,7 \%$ (Jacobina), porém não houve diferença estatisticamente significante $(p>0,21)$. Nenhum indivíduo apresentou anticorpos anti-HTLV-Il. Em conclusão, a prevalência da infecção pelo HTLV-I no interior do Estado da Bahia foi baixa, contudo, a população da cidade de Jacobina apresentou a maior prevalência. No entanto, outros estudos epidemiológicos, clínicos e virológicos serão necessários para a melhor compreensão da história natural desta infecção em Jacobina.
\end{abstract}

Palavras-chaves: HTLV-I. HTLV-II. Retrovírus. Soroprevalência. Bahia.

\begin{abstract}
The city of Salvador, capital of Bahia, presents a population with the highest prevalence of HTLV-I infection in Brazil. Untill now, only one study has investigated this infection in other cities of this state, even though by using a small sample. With objective to evaluate the prevalence of HTLVI/II antibodies in four cities of the state of Bahia. Serum samples from 1,539 individuals who lived in Catolândia, Ipupiara, Jacobina and Prado were screened by ELISA, and repeatedly reactive samples confirmed by Western Blot. Forty-seven (3.1\%) samples were positive by ELISA, and 44 of them were tested by Western blot: $5(0.3 \%)$ were positive, $8(0.5 \%)$ were indeterminate (all of them from Jacobina) and 31 were negative. The overall prevalence of HTLV-I antibodies was $0.3 \%$. This prevalence varied from $0.0 \%$ (Prado) to $0.7 \%$ (Jacobina), but differences were not statistically sgnificant $(p>0.21)$. None of these individuals presented HTLV-II antibodies. Jacobina showed the highest prevalence of HTLV-I infection among the cities studied, although the overall prevalence was low. In conclusion, further epidemiological, clinical and virological studies will be of paramount importance to obtain a better understanding of the natural history of this infection in Jacobina.
\end{abstract}

Key-words: HTLV-I. HTLV-II. Retrovirus. Sero-prevalence. Bahia.

Faculdade de Medicina da Universidade Federal da Bahia e Laboratório Avançado de Saúde Pública/FIOCRUZ. Salvador, BA. Fontes de financiamento: CNPq e CAPES (PET-Medicina)

Endereço para correspondência: Dr. José Tavares-Neto. Faculdade de Medicina/Hospital Univ. Prof. Edgard Santos. Campus UFBA do Canela. 40110-160 Salvador, BA. Telfax: (071) 247-4391.

Recebido para publicação em 17/04/97. 
Os vírus linfotrópicos de célula $T$ humana (HTLV), tipo I (HTLV-I) e II (HTLV-II), da família Retroviridae, têm distribuição variável conforme a população estudada20. O HTLV-II não foi associado a doença humana, porém o HTLV-I foi associado a leucemia/linfoma de célula $T$ do adulto, a paraparesia espástica tropical, entre outras patologias 7 .

A infecção pelo HTLV-I tem período de latência prolongado, até por algumas décadas ou por toda a vida do indivíduo infectado7. Neste período de latência, o marcador sorológico utilizado na prática clínica é a presença de anticorpos séricos anti-HTLV-I7. Em populações sadias do Brasil, os indivíduos soropositivos tiveram freqüências variando de $0 \%$ a $0,9 \% 1281518$. Mais recentemente, Galvão-Castro e cols 10 verificaram, entre os doadores de sangue da cidade do SalvadorBahia, a maior soroprevalência $(1,35 \%)$ de portadores de anticorpos anti-HTLV-I do Brasil, quando comparada com às freqüências entre os doadores de Manaus ( $0 \%)$, Recife $(0,33 \%)$, Rio de Janeiro $(0,33 \%)$ e Florianópolis $(0,08 \%)$. Anteriormente, Moreira Jr e cols 19 também pesquisaram anticorpos anti-HTLV em vários grupos populacionais sadios da cidade do Salvador e em 44 moradores da cidade de Jacobina, sendo a freqüência geral de soropositivos de $1,8 \%$ e de $2,3 \%$ entre os habitantes de Jacobina. Apesar das freqüências elevadas de soropositivos no Estado da Bahia, entre habitantes das cidades do Salvador8 1019 e de Jacobina 19 , outros estudos soroepidemiológicos não foram realizados em populações sadias das demais regiões do Estado. Por esta razão realizamos o presente estudo, especialmente porque as diferentes regiões do Estado da Bahia tiveram significativas influências sócioculturais e de constituição racial3.

\section{MATERIAL E MÉTODOS}

Considerando características históricas, sócio-econômicas e antropológicas 3 quatro cidades do interior do Estado foram selecionadas: a) Catolândia, região Oeste do Estado e a 916km de Salvador; b) Ipupiara, na região da Chapada Diamantina (região central do Estado) e distante $613 \mathrm{~km}$ de Salvador; c) Jacobina, a $330 \mathrm{~km}$ de Salvador, na região do Piemonte da Diamantina (região mais próxima à região nordeste do Estado) e d) a cidade do Prado, na região do Extremo Sul, distando $812 \mathrm{~km}$ de Salvador6. A seleção das amostras do estudo seccional variou em cada cidade: 1 . em Catolândia foram selecionadas ao acaso 709 amostras séricas, coletas em julho de 1990, entre as amostras de 1.273 de moradores da área endêmica de esquistossomose mansônica23; 2 . as amostras de Ipupiara $(n=325)$ e Prado $(n$ = 223) foram coletadas, respectivamente, em julho e dezembro de 1995; em ambos os municípios, os moradores do primeiro e do décimo domicílio, de cada quadra da área urbana foram incluídos no estudo; 3 . e as amostras séricas $(n=282)$ de Jacobina foram coletadas em julho de 1989 , segundo a metodologia descrita por Pollitzer e cols21, e selecionadas ao acaso os membros de 56 famílias entre as 493 famílias nucleares completas (pais e filhos).

As amostras séricas foram obtidas após o consentimento de cada indivíduo, anteriormente, palestras sobre os objetivos da investigação foram realizadas em escolas e/ou clubes comunitários 4 .

O questionário foi preenchido no momento da coleta da amostra sangüínea, anotando gênero, grupo racial (segundo Krieger e cols13), idade (conforme as recomendações de Tavares-Neto e Prata24, em trabalhos de campo), viagens (ou residências) para outros Estados do Brasil, internações hospitalares, uso de transfusões sangüíneas ou de hemoderivados, uso de drogas injetáveis, e antecedentes de doenças sexualmente transmissíveis 4 .

A pesquisa de anticorpos anti-HTLV-I/II foi realizada pelo exame imunoenzimático (ELISA, HTLV-I/II rp21 ELISA Ortho Diagnostics $\AA^{\circledR}$ System Inc., Raritan, NJ). As amostras com valores de densidade óptica maiores ou iguais ao valor de cut-off determinado pelo fabricante, foram consideradas como positivas, e repetidas em duplicata. Após esta repetição, as amostras com resultados duplamente positivos ou somente um resultado positivo foram consideradas positivos pela técnica de ELISA. As amostraspositivas foram analisadas pelo teste de Western Blot (GLD HTLV BLOT 2.4 - Genelabs Diagnostics $\AA$, Singapore), o qual emprega como antígenos o lisado viral e as proteínas recombinantes do envelope GD21, rgp46-I (específica do HTLV-I) e rgp46-II (específica do HTLV-II). Neste teste, de Western Blot, os resultados esperados foram: a) soropositivo para o HTLV-I (presença de reatividade para produtos do "gag", p19 e/ou p24, e para dois produtos do "env", GD21 e rgp46-I); b) soropositivo 
para o HTLV-II (presença de reatividade para produtos do "gag", p19 e/ou p24, e para dois produtos do "env", GD21 e rgp46-II); c) soropositivo para o HTLV (reatividade para produtos do "gag", p19 e/ou p24, e do "env" GD21); d) indeterminado (presença de bandas específicas, porém sem ter alcançado os critérios referidos acima para a soropositividade) e e) soronegativo (ausência de reatividade para as bandas virais específicas).

Parte das amostras ELISA-positivas foram também testadas através do teste Western Blot da Cambridge Biotech ${ }^{\circledR}$ Corporation (Worcester, MA, USA), porém este teste não discrimina os dois tipos de vírus HTLV. Os critérios utilizados para a interpretação dos resultados foram semelhantes aos usados no Western Blot da Genelabs Diagnostics $\AA$, observando as recomendações do fabricante e a reatividade para os produtos do "gag" e do "env".

As diferenças foram consideradas significativas quando a probabilidade $(p)$ do erro tipo $I(\alpha)$ foi inferior ou igual a $5 \%(p \leq 0,05)$, nos testes nãoparamétricos (qui-quadrado com correção de Yates e teste exato de Fisher) e paramétrico (teste t de Student).

\section{RESULTADOS}

A presença de anticorpos anti-HTLV-I/II foi pesquisada (ELISA) em 1.539 amostras séricas, de residentes em quatro cidades do Estado da Bahia, sendo $47(3,1 \%)$ repetidamente positivas. Entre os moradores soropositivos, 42 (14,9\% 42/282) foram provenientes da cidade de Jacobina, dois $(0,3 \%$ - 2/709) da cidade de Catolândia, dois $(0,9 \%$ - 2/223) da cidade de Prado e um $(0,3 \%-1 / 325)$ da cidade de Ipupiara.

Três indivíduos soropositivos (ELISA), residentes na cidade de Jacobina, foram excluídos do estudo, porque não houve volume suficiente de soro para realizar o teste confirmatório (Western Blot) e diferenciar entre o HTLV-I e o HTLV-II. Deste modo, 44 amostras foram submetidas ao teste de Western Blot (Genelabs $\AA$ ) e apenas cinco amostras foram confirmadas como positivas, oito foram indeterminadas e 31 negativas. Das 44 amostras ELISA-positivas, 20 foram também testadas através do teste Western Blot (Cambridge Biotech $\AA$ ), sendo 11 positivas, cinco indeterminadas e apenas quatro foram negativas. No entanto, o Western Blot (Genelabs $\AA$ ) somente confirmou cinco entre as 11 amostras soropositivas pelo
Western Blot (Biotech $\AA)$. A concordância observada entre os dois testes (Genelabs e Biotech) confirmatórios foi de $40 \%$.

Das cinco amostras positivas (Western Blot, Genelabs $\left({ }^{\circledR}\right)$, quatro foram discriminadas como HTLV-I, e em uma delas (da cidade de Catolândia) não foi possível fazer esta diferenciação, pois a mesma não apresentou reação com as proteínas rgp46-I ou rgp46-II.

As oito amostras de soro com resultados indeterminados (Western Blot, Genelabs ${ }^{\circledR}$ ) foram de moradores da cidade de Jacobina, e, entre elas, sete apresentaram reatividade para a proteína viral GD21, enquanto que três destas sete apresentaram reatividade concomitante para a proteína rgp46-I, específica do HTLV-I. A oitava amostra apresentou reatividade exclusivamente para a rgp46-I.

Portanto, a soroprevalência de anticorpos anti-HTLV-I na população global estudada foi de $0,26 \%(4 / 1.536)$. Considerando o morador com anticorpos anti-HTLV-I/II, a soroprevalência foi de $0,32 \%(5 / 1.536)$. A maior freqüência de soropositivos HTLV-I foi observada entre os indivíduos da cidade de Jacobina $(0,7 \%$ 2/279), todavia, não houve diferença estatisticamente significante (teste exato de Fisher, $p>0,21$ ), quando comparada com as freqüências observadas entre os moradores das outras cidades estudadas: Catolândia (1/709); Ipupiara (1/325) e Prado (0/223).

Os cinco indivíduos soropositivos (4 HTLV-I e 1 HTLV-I/II) tiveram idades entre 37 e 67 anos, com idade média de 49,2 $\pm 11,1$ anos, sendo significativamente maior $(t=3,33 p<$ 0,001 ) do que a idade média da população estudada (32,6 $\pm 19,4$ anos). A proporção de soropositivos do gênero masculino $(2 / 696)$ foi semelhante (teste exato de Fisher, $p>0,81$ ) a do gênero feminino (3/843).

$\mathrm{Na}$ Tabela 1, consta a distribuição racial das quatro populações estudadas e o número de indivíduos soropositivos (HTLV-I ou HTLV-I/II) e com sorologia indeterminada, mostrando a freqüência maior de indivíduos negros na cidade litorânea do Prado, e as freqüências progressivamente maiores de mestiços de índio proporcional ao aumento da distância da cidade (Jacobina, Ipupiara e Catolândia) da região litorânea do Estado. A freqüência $(0,34 \%)$ de soropositivos (HTLV-I e I/II) entre os indivíduos dos grupos raciais não-brancos (4/1171) foi semelhante (teste exato de Fisher, $p>0,73$ ) à freqüência $(0,27 \%)$ de soropositivos brancos $(1 / 368)$. 
Tabela 1 - Distribuição dos grupos raciais nas quatro populações estudadas do Estado da Bahia, e os respectivos números de indivíduos soropositivos para o HTLV-I (I), HTLV-I/II (I/II) e com sorologia indeterminada (ID).

\begin{tabular}{|c|c|c|c|c|c|c|c|c|c|c|}
\hline \multirow{4}{*}{$\begin{array}{l}\text { Grupo racial } \\
\text { Branco }\end{array}$} & & & \multicolumn{8}{|c|}{ Cidade $\mathrm{n}(\%)$} \\
\hline & \multicolumn{2}{|c|}{ Sorologia } & \multirow{2}{*}{\multicolumn{2}{|c|}{$\begin{array}{c}\text { Catolândia } \\
(\mathrm{n}=709)\end{array}$}} & \multirow{2}{*}{\multicolumn{2}{|c|}{$\begin{array}{l}\text { Ipupiara } \\
(\mathrm{n}=325)\end{array}$}} & \multirow{2}{*}{\multicolumn{2}{|c|}{$\begin{array}{l}\text { Jacobina } \\
(\mathrm{n}=282)\end{array}$}} & \multirow{2}{*}{\multicolumn{2}{|c|}{$\begin{array}{l}\text { Prado } \\
(n=223)\end{array}$}} \\
\hline & HTLV & (n) & & & & & & & & \\
\hline & $\mathrm{I}(1)$ & $\mathrm{ID}(2)$ & 141 & $(19,9)$ & 125 & $(38,5)$ & 65 & $(23,0)$ & 37 & $(16,6)$ \\
\hline Mestiço índio & $\mathrm{I} / \mathrm{II}(1)$ & - & 67 & $(9,5)$ & 29 & $(8,9)$ & 8 & $(2,8)$ & 1 & $(0,5)$ \\
\hline Mulato-claro & $\mathrm{I}(2)$ & $\mathrm{ID}(3)$ & 299 & $(42,2)$ & 109 & $(33,5)$ & 104 & $(36,9)$ & 71 & $(31,8)$ \\
\hline Mulato-médio & $\mathrm{I}(1)$ & $\mathrm{ID}(2)$ & 154 & $(21,7)$ & 38 & $(11,7)$ & 66 & $(23,4)$ & 57 & $(25,6)$ \\
\hline Mulato-escuro & - & $\mathrm{ID}(1)$ & 42 & $(5,9)$ & 21 & $(6,5)$ & 32 & $(11,4)$ & 32 & $(14,3)$ \\
\hline Negro & - & - & 6 & $(0,8)$ & 3 & $(0,9)$ & 7 & $(2,5)$ & 25 & $(11,2)$ \\
\hline
\end{tabular}

Entre os indivíduos HTLV-positivos, apenas dois, da cidade de Jacobina, pertenciam à mesma família (marido e mulher). Nesta família, quatro filhos do casal não apresentaram anticorpos anti-HTLV-I/II.

Dos oito indivíduos com resultados "indeterminados", seis deles apresentaram idades entre 18 e 22 anos, e dois com idades superiores a 50 anos. Os pais de todos os casos $(n=6)$ com idades entre 18 e 22 anos foram HTLV-I/II negativos. Entre estes casos, houve predominância do gênero masculino ( $\mathrm{M}: \mathrm{F}=$ $6: 2)$.

Todos os soropositivos estavam aparentemente hígidos, sem história atual ou anterior de doença neurológica ou de neoplasias. Não foram disponíveis os dados sobre transfusão sangüínea, uso de drogas e doenças sexualmente transmissíveis dos residentes em Jacobina. Nas outras cidades, nenhum dos indivíduos incluídos no estudo referiu antecedente de transfusão sangüínea. Um indivíduo soropositivo para HTLV-I (de Catolândia) tinha história passada de sífilis. O uso de drogas injetáveis não foi referido apenas dois moradores, ambos soronegativos, residentes na cidade de Prado, informaram história de uso de cocaína, via inalatória, porém negaram o uso de drogas injetáveis. Entre os cinco soropositivos, dois referiram residência anterior na cidade de São Paulo e um deles também em Goiânia.

\section{DISCUSSÃO}

O presente estudo demonstrou que a freqüência de portadores de anticorpos antiHTLV-I nas cidades pesquisadas, com exceção à da cidade de Jacobina $(0,7 \%)$, foi nula ou baixa $(0,0 \%$ a $0,3 \%)$. A discrepância de resultados observados em Jacobina, no presente trabalho e por Moreira $\mathrm{Jr}$ e cols ${ }^{19}$ (de
$2,3 \%$, pode ser atribuída as diferenças metodológicas (tamanho amostral e testes diagnósticos) entre as duas investigações. Também a freqüência de soropositivos detectada em Jacobina $(0,7 \%)$ foi menor do que as freqüências $(0,9 \%|| 2,2 \%)$ entre outros grupos populacionais da cidade do Salvador8 10 19. Entretanto, como todos os sete indivíduos com resultados indeterminados (Western Blot, Genelabs $\AA$ ) foram da cidade de Jacobina, e na hipótese que tais resultados podem representar soroconversão, a soroprevalência de portadores de anticorpos anti-HTLV-I/II aumentaria para $3,2 \%(9 / 279)$, sendo significativamente maior $\left(\chi^{2}=4,54 p<0,04\right)$ do que a descrita $(1,35 \%)$ por Galvão-Castro e cols 10 em doadores de sangue de SalvadorBahia, mas semelhante $(p>0,05)$ a observada por Moreira Jr e cols 19 em Jacobina. Todavia, a hipótese dos indivíduos com sorologia indeterminada corresponder a soroconversão deve ser considerada com cautela; porque, estes resultados indeterminados podem corresponder a soropositividade inespecífica ${ }^{14}$, como será discutido adiante.

No entanto, estes resultados em diferentes localidades do Estado da Bahia reforçaram as observações de Mueller20, que classificou o Brasil como país de baixa ou de muito baixa endemicidade para o HTLV-I. Em especial entre as populações das cidades menores, onde provavelmente os fatores associados à exposição ao vírus HTLV-I são menos freqüentes e, em decorrência, a transmissão é também menos freqüente. Por isto, a situação epidemiológica da população da cidade de Jacobina necessita ser investigada, com o objetivo de explicar quais os fatores de risco envolvidos.

Por outro lado, o número de resultados falso-positivos pelo ELISA foi elevado no presente estudo, já que das 44 amostras 
repetidamente positivas 39 não foram confirmadas como positivas, através do Western Blot (Genelabs ${ }^{\circledR}$ ). Resultados falso-positivos pelo ELISA têm sido relatados, com vários testes disponíveis comercialmente e de diferentes fabricantes 5 . Também os sucessivos procedimentos de congelamento/descongelamento e a estocagem por período prolongado das amostras séricas podem causar aderência inespecífica de imunoglobulinas à fase sólida, durante a realização do teste de ELISA ${ }^{14}$. O que poderia explicar o número elevado de falso-positivos, no presente estudo, especificamente com as amostras da cidade de Jacobina, pois foram coletadas em 1989 e nos últimos sete anos foram utilizadas em outras investigações. No entanto, as amostras de Catolândia23 foram expostas aos mesmos procedimentos e resultados falsos-positivos não foram observados.

Outra possível causa de resultados falsopositivos pelo ELISA é a reação cruzada com os anticorpos contra os antígenos do sistema de histocompatibilidade (HLA), já que os lisados virais podem conter antígenos HLA da célula usada para propagar o vírus ${ }^{14}$. Uma outra causa de resultados falso-positivos é a reatividade com a proteína recombinante (rp21E), derivada da proteína transmembrana, secundária a reação de anticorpos contra antígenos bacterianos (de contaminantes das amostras séricas), já que para a produção desta proteína por tecnologia recombinante são usadas bactérias ${ }^{14}$.

Em regiões endêmicas para a malária foram descritos resultados falso-positivos para o HTLV-I, pelo ELISA16. O município de Jacobina é área endêmica para leishmaniose visceral, esquistossomose mansônica e tripanosomíase, mas não de malária. Porém, no município de Catolândia a esquistossomose mansônica é endêmica 23 e os resultados falsos-positivos não foram freqüentes como em Jacobina. Todavia, não encontramos na literatura relatos de reação sorológica cruzada em portadores destas outras endemias e a infecção pelo HTLV-I/II.

Segundo Lal14, todos os indivíduos com resultados indeterminados pelo Western Blot, que apresentam reatividade para a proteína GD21 e/ou para a proteína p19 devem ser retestados a cada seis meses, pois este padrão pode ser indicativo de uma soroconversão. A presença de reatividade exclusivamente para a proteína recombinante GD21 pode representar a fase precoce de produção de anticorpos durante a soroconversão14. Conseqüentemente, a possibilidade de soroconversão entre estes indivíduos não foi excluída, apesar das mães de cinco destes indivíduos serem soronegativas.

$\mathrm{Na}$ literatura também foram descritos casos de resultados falso-positivos, através de alguns testes confirmatórios, entre estes 0 Western Blot da Cambridge Biotech $\AA$ e 0 Western Blot da Genelabs ${ }^{\circledR} 14$. Portanto, a possibilidade de resultados falso-positivos e de falso-negativos deve ser considerada tanto no âmbito da pesquisa, como na prática clínica, optando-se, sempre que possível, pelos testes com as melhores características operacionais, levando-se em consideração a relação custo-benefício. Além disto, o índice de resultados concordantes do Western Blot da Cambridge Biotech $\AA^{\circledR}$ foi baixo (40\%).

A prevalência mais elevada da infecção pelo HTLV-I em Salvador10 e em Jacobina poderia ser explicada pelo fato de que ambas as cidades são formadas por populações predominantemente de constituição racial negra, e de que o HTLV-I pode ter sido introduzido no Estado da Bahia a partir de escravos africanos 9 . Todavia, no presente estudo, não observamos freqüência significante de portadores de grupos raciais negróides com anticorpos anti-HTLV-I, como relatada em outras regiões do mundo16. Além disto, na amostra estudada, a maior freqüência de indivíduos mulatos e negros foi observada na cidade do Prado, onde não foram detectados casos de infecção pelo HTLV-I. Todavia, em análise preliminar, os doadores de sangue soropositivos (ELISA) para o HTLV-I/II naturais de Salvador, Bahia apresentaram maior constituição racial negra do que os doadores soropositivos de outras cidades da Bahia22.

A hipótese da origem africana do HTLV-I, explicando a maior freqüência de soropositivos entre as populações negras 9 foi contestada por outros autores que estudaram populações asiáticas isoladas ou reviram dados populacionais de várias partes do mundo11 12. Já a infecção pelo HTLV-II parece ser mais freqüente em populações indígenas das Américas, inclusive do Brasil17, sugerindo que a infecção pelo HTLV-II no continente americano é muito antiga, e, deste modo, anterior ao tráfico mercantilista de escravos, procedentes da África. No entanto, nas duas cidades (Ipupiara e Catolândia) da Bahia com maior contingente de pessoas mestiças de índio, as freqüências de portadores de HTLV-II foram nulas (ou muito baixa, se o caso de Catolândia com anticorpos anti-HTLV- 
I/II fosse confirmado como HTLV-II).

No presente estudo, todos os quatro indivíduos soropositivos para o HTLV-I apresentavam idade superior a 40 anos. Este resultado é compatível com o aumento da prevalência de anticorpos anti-HTLV-I proporcional ao aumento da idade, observado em diferentes áreas geográficas ${ }^{16}$. Nestes soropositivos não foi observada diferença na proporção entre os gêneros. Este resultado difere da maior parte dos estudos anteriores, que demonstraram predominância do gênero feminino entre os indivíduos infectados pelo HTLV-I; entretanto, Moreira Jr e cols ${ }^{19}$ não detectaram diferença na soroprevalência relacionada ao gênero, entre os indivíduos estudados do Estado da Bahia. Em áreas não-endêmicas do Japão foi observada predominância do gênero masculino entre os soropositivos para o HTLV-I16.

Os quatro indivíduos HTLV-I positivos deste estudo foram analisados, visando a identificação das possíveis vias de transmissão do vírus. A transmissão pela via parenteral é pouco provável, em todos os casos, já que os indivíduos de Catolândia e de Ipupiara negaram antecendentes de transfusão sangüínea ou de uso de drogas, e também as cidades estudadas não estão inseridas na rota de tráfico de drogas, e o consumo destas, se existente, deve ser muito baixo, particularmente o das drogas injetáveis. Além disto, as cidades de Catolândia e Ipupiara apresentam relativo isolamento geográfico, ao contrário das cidades do Prado (com razoável fluxo turístico) e de Jacobina (com escritórios de negociantes estrangeiros de pedras preciosas e semi-preciosas). Quanto aos casos de Jacobina, os dados sobre hemotransfusão ou uso de drogas não foram levantados. Todavia, não se pode excluir a possibilidade da transmissão vertical para os quatro indivíduos referidos, uma vez que as genitoras dos mesmos não foram testadas para a infecção pelo HTLV-I, neste estudo. Outra especulação seria a transmissão deste vírus através da amamentação por "mães de leite", prática comum em cidades do interior do Estado da Bahia.

O mais provável é que a via de transmissão, em todos estes casos, tenha sido a sexual, principalmente com relação aos membros do casal da cidade de Jacobina, ambos soropositivos para o HTLV-I. Contudo, para o caso HTLV-I positivo de Catolândia, do gênero masculino (e história pregressa de sífilis), foi excluída a possibilidade de transmissão da infecção a partir da esposa, já que a mesma foi soronegativa; enquanto que para o caso de Ipupiara, do gênero feminino, não foi possível excluir a transmissão através do esposo, já que o mesmo havia falecido.

Em conclusão, os nossos dados sugerem que, à exceção de Jacobina, a freqüência da infecção pelo HTLV-I e II, especialmente, em habitantes de cidades do interior do Estado da Bahia é muito baixa, e inferior à observada na população da cidade do Salvador. Por isto também, torna-se necessária a realização de estudo seccional na população de Jacobina, com amostra populacional representativa, seguido de estudo caso-controle para a avaliação de fatores de exposição que expliquem a freqüência maior de portadores de anticorpos anti-HTLV-I nesta cidade do Estado da Bahia.

\section{AGRADECIMENTOS}

As Dras. Karla Motta e Ana Emília TorresMorales pelo auxílio nas coletas das amostras de Ipupiara; ao técnico Zoroastro Teixeira, do Hospital Couto Maia, pelo auxílio nas coletas de Ipupiara e Prado; ao técnico Noilson Gonçalves, do LASP/FIOCRUZ, pela colaboração na realização dos testes sorológicos, e as Profas. Eliane Azevêdo e Angela Lima por terem cedido as amostras de Jacobina.

\section{REFERÊNCIAS BIBLIOGRÁFICAS}

1. Andrada-Serpa MJ, Dobbin JA, Gomes P, Linhares D, Azevedo JG, Hendriks J, Clayden SA, Rumjanek VM, Tedder RS. Incidence of retroviruses in some Brazilian groups. Immunology Letters 18:15-18, 1988.

2. Andrada-Serpa MJ, Tosswill J, Schor D, Linhares D, Dobbin J, Pereira MS. Seroepidemiologic survey for antibodies to human retroviruses in human and non human primates in Brazil. International Journal of Cancer 44:389-393, 1989.

3. Azevêdo ES, Fortuna CMM, Silva KMC, Sousa MGF, Machado MA, Lima AMVMD, Aguiar ME, Abé K, Eulálio MCMN, Conceição MM, Silva MCBO, Santos MG. Spread and diversity of human populations in Bahia, Brazil. Human Biology 54:329-341, 1982.

4. Britto APCR. Infecção pelo HTLV-I/II no Estado da Bahia. Dissertação de Mestrado, Universidade Federal da Bahia, 1997.

5. Busch MP, Laycock M, Kleinman SH, Wages Jr JW, Calabro M, Kaplan JE, Khabbaz RF, Hollingsworth CG. Retrovirus Epidemiology Donor Study. Accuracy of supplementary serologic testing for 
human T-lymphotropic virus types I and II in US blood donors. Blood 83:1143-1148, 1994.

6. Centro de Estatística e Informações (Bahia). Informações básicas dos municípios baianos. Secretaria de Planejamento, Ciência e Tecnologia/Governo do Estado da Bahia, 1994.

7. De Thé G. Épidémiologie biologique et clinique des in fections onco-rétrovirales HTLV-I et II. Bulletin de L'Academie Nationale de Médecine 175:861-870, 1991.

8. Dos Santos Jl, Lopes MAA, Deliége-Vasconcelos E, Couto-Fernandez JC, Patel BN, Barreto ML, Ferreira Jr OC, Galvão-Castro B. Seroprevalence of HIV, HTLV-I/II and other perinatally-transmitted pathogens in Salvador, Bahia. Revista do Instituto de Medicina Tropical de São Paulo 37:343-348, 1995.

9. Gallo RC, Sliski $\mathrm{AH}$, de Noronha CMC, de Noronha F. Origins of human T-lymphotropic viruses. Nature 320:219, 1986.

10. Galvão-Castro B, Loures L, Rodrigues LGM, Sereno A, Ferreira Jr OC, Franco LGP, Muller M, Sampaio DA, Santana A, Passos LM, Proietti F. Geographic distribution of human T-lymphotropic virus type-I among.blood donors: a brazilian nationwide study. Transfusion 37: 242-246, 1997.

11. Gessain A, De-Thé G. What is the situation of human T cell lymphotropic virus type II (HTLV-II) in Africa? Origin and dissemination of genomic subtypes. Journal of Acquired Immune Deficiency Syndromes and Human Retrovirology 13 (suppl 1): S228-235, 1996.

12. Ishida T, Yamamoto K, Omoto K. A seroepidemiological survey of HTLV-I in the Philippines. International Journal of Epidemiology 17:625-628, 1988.

13. Krieger $\mathrm{H}$, Morton NE, MI MP, Azevêdo E, FreireMaia A, Yasuda N. Racial admixture in north-eastern Brazil. Annals Human Genetics 29:113-125, 1965.

14. Lal RB. Delineation of immunodominant epitopes of human T-lymphotropic virus types I and II and their usefulness in developing serologic assays for detection of antibodies to HTLV-I and HTLV-II. Journal of Acquired Immune Deficiency Syndromes and Human Retrovirology 13 (suppl I):S170-S178, 1996.

15. Lee H, Anderson E, Allain JP, Gonzaga A. HTLV-I infection in Brazil. Blood 73:1742, 1989.

16. Levine PH, Blattner WA, Clark J, Tarone R, Maloney EM, Murphy EM, Gallo RC, Robert-Guroff M, Saxinger WC. Geographic distribution of HTLV-I and identification of a new high risk population. International Journal of Cancer 42: 7-12, 1988.

17. Maloney EM, Biggar RJ, Neel JV, Taylor ME, Hahn $\mathrm{BH}$, Shaw GM, Blattner WA. Endemic Human T cell Lymphotropic Virus type II infection among isolated Brazilian Amerindians. The Journal of Infectious Diseases 166: 100-107, 1992.

18. Matutes E, Schulz T, Andrade-Serpa MJ, Araújo AQC, Pombo de Oliveira MS. Report of the second international symposium on HTLV in Brazil. Leukemia 8: 1092-1094, 1994.

19. Moreira Jr ED, Ribeiro TT, Swanson P, Sampaio-Filho C, Melo A, Brites C, Badaró R, Toedter G, Lee H, Harrington Jr W. Seroepidemiology of human T-cell lymphotropic virus type I/II in Northeastern Brazil. Journal of Acquired Immune Deficiency Syndromes 6:959-963, 1993.

20. Mueller N. The epidemiology of HTLV-I infection. Cancer Causes and Control 2: 37-52, 1991.

21. Pollitzer WS, Azevêdo ES, Barefoot J, Lima AMVMD, Carvalho RDS, Santos MIG, Eulalio MCMN. Characteristics of a population sample of Jacobina, Bahia, Brasil. Human Biology 54:697-707, 1982.

22. Santos-Torres S, Straatmann A, Santna A, TavaresNeto J. Mistura racial negra em portadores de anticorpos anti-HTLV-I/II da Bahia. In: Anais do XXXIII Congresso da Sociedade Brasileira de Medicina Tropical, Belo Horizonte, p. 173, 1997.

23. Tavares-Neto J. Estudo soro-epidemiológico do vesiculovírus Piry na população e entre os membros das famílias nucleares, em CatolândiaBahia. Tese de Doutorado. Universidade de São Paulo, Ribeirão Preto, SP, 1992.

24. Tavares-Neto J, Prata A. A idade como causa de erro em inquéritos populacionais. Revista da Sociedade 